\title{
Effect of light-converting coatings on the growth of Sarepta mustard (Brassica juncea L.) plants colonized by associative microorganisms
}

\author{
Natalia Zakharchenko ${ }^{1,}$, Sergey Anisimov ${ }^{2}$, Ivan Dyadishchev ${ }^{3}$, Sergey Ponomarenko ${ }^{3}$, and \\ Robert Khramov ${ }^{2}$ \\ ${ }^{1}$ Branch of Shemyakin-Ovchinnikov Institute of Bioorganic Chemistry, Russian Academy of \\ Sciences, Science Avenue 6, 142290 Pushchino, Russia \\ ${ }^{2}$ Institution of Theoretical and Experimental Biophysics, Russian Academy of Sciences, Science \\ Avenue 3, 142290 Pushchino, Russia \\ ${ }^{3}$ Enikolopov Institute of Synthetic Polymeric Materials, Russian Academy of Sciences, \\ Profsoyuznaya str. 70, 117373 Moscow, Russia
}

\begin{abstract}
The effect of colonization by beneficial associative microorganisms Pseudomonas putida KT 2442 and Rhodococcus erythropolis X5 on the growth of Sarepta mustard (Brassica juncea L.) under a covering light-converting material containing organic photoluminophore, in vitro and in vivo, was investigated. The combined use of microbial colonization and photoluminophore coating led to stimulation of plant growth much stronger (2.4 times more) than separately only photoluminophoric coating (1.3 times) or colonization (2.1 times). These data indicate that when covering materials with photoluminophores are used in agrobiotechnologies, luminescent red light $(610-730 \mathrm{~nm})$ induces an increase in biochemical processes not only in plants, but also in microorganisms that supply plants with growth regulators and other useful metabolites. The data obtained are relevant for further study of the photobiological mechanisms of interactions between the plantmicroorganism system in agrobiotechnologies.
\end{abstract}

\section{Introduction}

The use of light-correcting coatings is a promising method of increasing crop yields [1, 2]. The influence of coatings on the development of plants is associated with a change in the spectral composition of the electromagnetic radiation of the sun passing through them - the absorption of the ultraviolet component and its transformation into the red region of the spectrum [3]. At the same time, there is a change in the structure of membranes, their permeability increases, contributing to an increase in the effectiveness of cytokinins and gibberellins, leading to increased cell division. In natural conditions, plants exist in close association with a complex of soil microorganisms that have a stimulating effect on the growth and development of plants. This process is associated with the ability of microorganisms to nitrogen fixation, mobilize nutrients from the soil, produce

\footnotetext{
*Corresponding author: znata_2008@mail.ru
} 
physiologically active substances, suppress the growth of phytopathogens and detoxify alien chemicals [4-6]. Previously, it was shown that sunlight that passed through the lightcorrecting film and transformed by photoluminophores stimulates growth processes, population dynamics and oxygenase activity of indigenous soil microflora during oil degradation on the example of Pseudomonas strains [7, 8]. It is possible that during the growth of agricultural plants under light-correcting films, not only the plants themselves, but also microorganisms associated with them - methylobacteria, pseudomonas, rhodococci and many others are exposed to the influence of transformed light. The role of microbiota in stimulating plant growth with light-converting coatings has not yet been investigated in details.

The purpose of our work was to perform a comprehensive investigation of the effect of light-correcting films with photoluminophoric coating with a maximum emission of $660 \mathrm{~nm}$ on the growth of plants associated with certain strains of microorganisms.

\section{Materials and methods}

\subsection{Plant material}

The objects of research were the plants of Sarepta mustard (Brassica juncea L.) of the Russian variety. The seeds were sterilized for $1 \mathrm{~min}$ in $70 \%$ ethanol, then 2 min in a $20 \%$ solution of sodium hypochlorite and washed 3 times (10 min each) in sterile distilled water. The seeds were germinated on a hormone-free Murashiga-Skoog (MS) medium containing 7 $\mathrm{g} / \mathrm{L}$ of agar, $30 \mathrm{~g} / \mathrm{L}$ of sucrose $(\mathrm{pH} 5.8)$ and a standard set of salts [9]. The plants were cultivated at a temperature of $22-24^{\circ} \mathrm{C}$, a 16 -hour day and illumination of $2000 \mathrm{~lx}$. The source of illumination is fluorescent lamps LB-40 (Russia). In a series of experiments in the open ground (September-October, 2021), light-converting agrotextiles were used: polypropylene non-woven spunbond $30 \pm 3 \mathrm{~g} / \mathrm{m}^{2}$, coated with polylactide varnish with a content of $0.25 \%$ of the new organic photoluminophore (PL) with a concentration of $0.25 \%$ and absorption mainly in the band $460-560 \mathrm{~nm}$, and re-emitting with a spectral maximum of $660 \mathrm{~nm}$ with a half-width spectrum of 610-730 nm. As PL, luminescent molecules of donor-acceptor type based on triphenylamine with effective radiation in the red range were used [10, 11]. Spunbond without PL was used as a control.

\subsection{Colonization of plants by associative microorganisms}

For colonization, bacterial strains Pseudomonas putida KT 2442 (pNF142::TnMod) [13] and Rhodococcus erythropolis X5 [14], obtained from the Laboratory of Plasmid Biology of the G.K. Scriabin Institute of Biochemistry and Physiology of Microorganisms of the Russian Academy of Sciences, were used. The bacteria were grown on LB medium [15]. Sterile monthly leaves of Brassica juncea plants were sprayed with cell suspension $\left(10^{3}-10^{5}\right.$ $\mathrm{CFU} / \mathrm{mL}$ ) of the bacteria P. putida KT 2442 and $R$. erythropolis X5. The plants were placed in glass tubes (each variant of 40 pieces) with an agarized MS medium and cultured at $22^{\circ} \mathrm{C}$ $-24^{\circ} \mathrm{C}$, illumination of $2000 \mathrm{~lx}$ in a 16-hour daytime photoperiod. Microbiological testing of various plant explants (leaves, root) was carried out after 7, 14 and 25 days after colonization by the Kandel method [16]. For this purpose, a plant extract obtained by homogenizing 100 mg of plant tissue was applied to the surface of a solid LB medium with selective antibiotics in Petri dishes and incubated at $22^{\circ}-24^{\circ} \mathrm{C}$. After 2 days, the number of colony-forming units (CFU) per $1 \mathrm{~g}$ of wet weight was calculated. 


\subsection{Statistical analysis}

Statistica v.6.0 and MS Excel 2007 were used for statistical data processing. Measurements were made in three biological and three analytical repetitions. Graphs and diagrams show the average values and their standard deviations. The reliability of the differences was assessed by the non-parametric Mann-Witney criterion.

\section{Results and discussion}

In the laboratory, sterile monthly mustard plants grown from seeds were colonized with bacterial strains of P. putida KT 2442 and Rh. erythropolis X 5 under in vitro conditions. For this plant, a single spray with a suspension of one of the bacteria with a titer of cells of $10^{3}$ $10^{5}$ was applied. After that, the test tubes with plants were covered with red (containing PL coating) and or white (without PL coating) spunbond. 20 tubes of colonized plants and 20 tubes of uncolonized ones were put under each of the spunbond. After 7, 14 and 21 days, testing was carried out to establish an associative relationship of the bacteria with plants in vitro. To do this, extracts obtained from colonized plants grown under different covering material - with PL and without PL, were applied to the surface of the nutrient medium with selective antibiotics in Petri dishes and incubated for 2 days at a temperature of $22-24^{\circ} \mathrm{C}$. In 3 weeks after colonization of the mustard by $P$. putida bacteria, their population on the roots increased under the coating with PL from $5.0 \times 10^{2}$ (in the $1^{\text {st }}$ week) to $4.2 \times 10^{3} \mathrm{CFU} / \mathrm{g}$ of raw mass, and under the coating without PL from $4.0 \times 10^{2}$ to $3.0 \times 10^{3}$. The photoluminophore coating on the spunbond stimulated the growth of bacteria by 1.5 times (Fig. 1A).

At the end of the experiment in the roots of plants, the population of bacteria became an order of magnitude greater than in the leaves of Fig. 1 A, B. When colonizing plants with the $R h$. erythropolis strain, the bacteria were distributed almost equally in the leaves and in the roots, but with PL coating, the number of bacteria in the leaves $\left(2.7 \times 10^{3}\right)$ and roots $(2.4 \mathrm{x}$ $\left.10^{3}\right)$ increased by more than 1.5 times compared to the coating without PL $\left(1.6 \times 10^{3}\right.$ and 1.8 $\mathrm{x} 10^{3}$ ), which indicates the stimulating effect of red light $660 \mathrm{~nm}$ on the growth of bacteria during colonization of the plants.

Investigation of the rate of bacterial growth under the PL coating separately from the colonization (Fig. 2) revealed that irradiation of $P$. putida with light transformed by a lightcorrecting film increases their population by 1.5 times as compared to control variants (under coating without PL and growth without coating). The data obtained indicate on photostimulation of the growth of these microorganisms. These data also confirm the investigation results reported earlier on the example of strains of Pseudomonas putida and Pseudomonas stutzeri [8]. The use of Rh. erythropolis X5 strain for the colonization of plants we report here for the first time. Despite the fact that plant growth doubled with colonization by this strain together with the action of red light of the photoluminophore coating, its growth rate under the PL coating was lower than in the control experiment. This result could be related to its genetic modification, since this strain contains a plasmid with the green fluorescent protein (GFP) gene, the amplification of which is an energy-consuming process.

Plants colonized with strains of P. putida and Rh. erythropolis showed an increased growth rate as compared to control non-colonized plants, as can be seen in Figures 3 and 4. Moreover, the plants colonized with $P$. putida and growing under PL coating were more than 2 times taller than the non-colonized, cultivated without PL $(4.3 \pm 0.4$ and $2.0 \pm 0.2 \mathrm{~cm}$, respectively). It was found an order of magnitude more bacteria in the roots than in the leaves. During the colonization of plants with the Rh. erythropolis strain, the bacteria were distributed almost equally in the leaves and in the roots. However, with the photoluminescent coating, the number of bacteria in the leaves and the roots increased almost 2 times as 
compared to those under the coating without PL, which indicates a stimulating effect of red light of $660 \mathrm{~nm}$ on the growth of bacteria during colonization of plants. Both strains studied stimulated the growth of plants under the PL coating and, accordingly, plants growing without PL coating lagged behind in growth. Red light is known to stimulate bacterial growth - enhancing nucleic acid synthesis and cell respiration intensity, which can cause certain changes in the metabolic regulation program [16]. We can assume that with the intensification of metabolic processes in bacteria irradiated with transformed PL light, greater accumulation of physiologically active substances occurs as well as mobilization of nutrients from the environment or soil is enhanced, which favorably affects the growth of plants. Thus, the average height of 1.5 monthly colonized $P$. putida $(4.3 \pm 0.4)$ and $R h$. erythropolis $(3.9 \pm 0.2)$ plants under PL was 2.2 times greater than that of the noncolonized $(2.0 \pm 0.2$ and $1.8 \pm 0.2)$ (Fig. 3,4$)$.

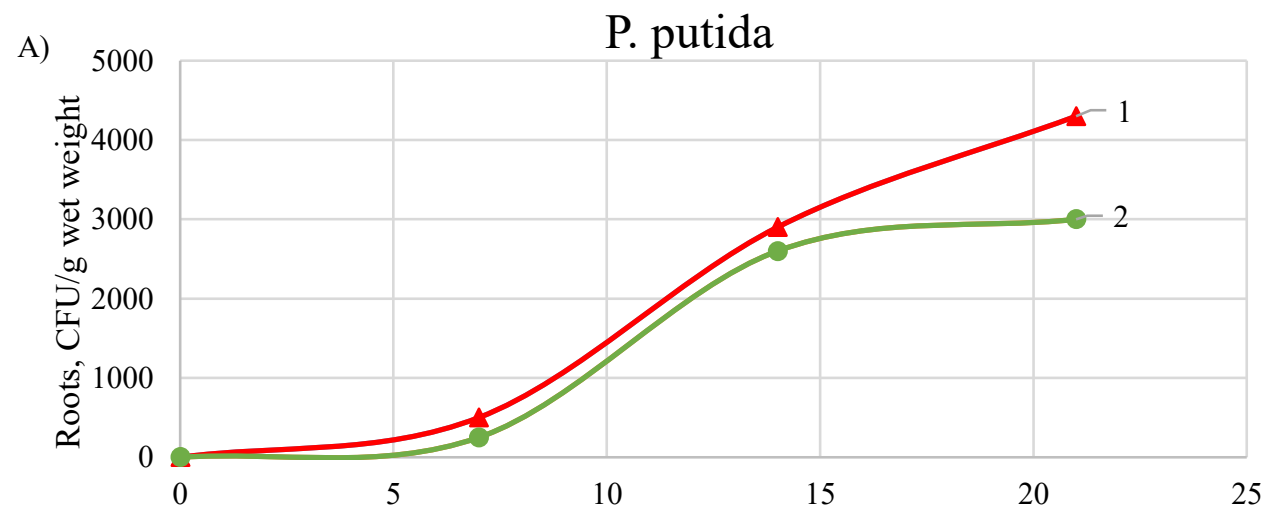

Experiment duration, days

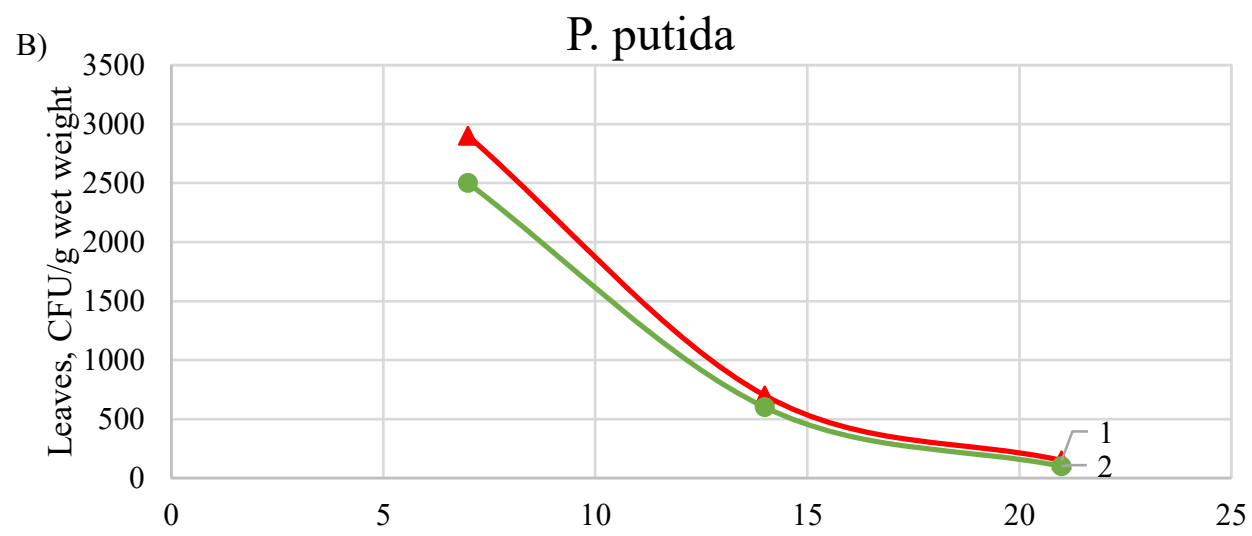

Experiment duration, days

Fig. 1. The number of $P$. putida bacteria on mustard roots and leaves after colonization in vitro per $1 \mathrm{~g}$ of wet weight. A - the number of bacteria in the roots; B - the number of bacteria in the leaves. The numbers 1,2 - respectively, indicate the options with PL containing and without PL containing spunbonds. 
A)

\section{P. putida}

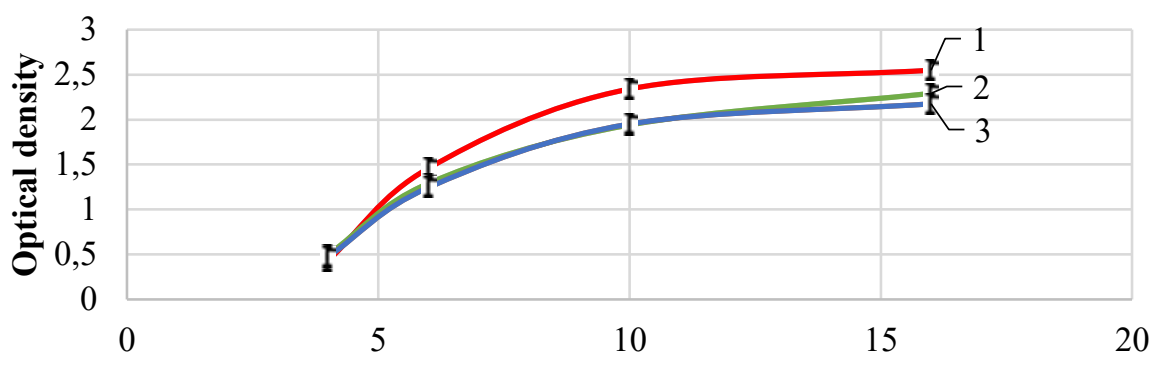

Experiment duration, hour

\section{Rh. erythropolis}

B)

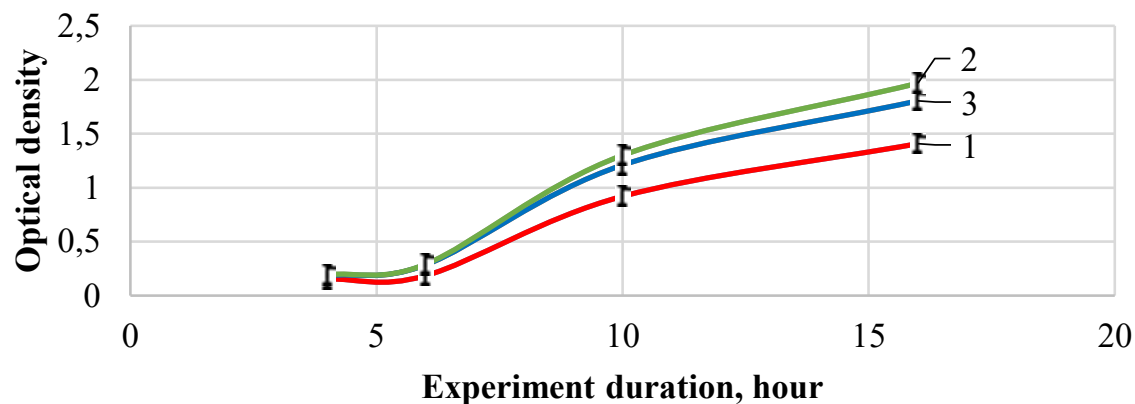

Fig. 2. Change in the optical density of P. putida (A) and Rh. erythropolis (B) during the growth of bacteria under different coatings. 1 - under the spunbond with PL; 2 - without a spunbond; 3- under the spunbond without PL.

In order to determine the effect of associative bacteria on the growth and development of mustard plants under the influence of photoluminescent coatings and their adaptation under conditions of closed and open ground, colonized plants from sterile conditions were planted in the closed ground of the Artificial Climate Station "Biotron" of the FIBH RAS and in the open ground on experimental plots in Pushchino, Moscow Region, Russia. When plants were transferred from in vitro conditions to Biotron and open ground, the colonized ones adapted better and the growth trend continued (Fig. 5 A, B). These data indicate a joint positive effect of associative bacteria and light-converting coatings on the growth and morphogenesis of the plants.

Thus, it was shown that the light that passed through the light-correcting film and transformed by the photoluminophores emitting with a maximum at $660 \mathrm{~nm}$ and a half-width of the spectrum at $610-730 \mathrm{~nm}$ stimulates the growth processes of plants and microorganisms, while combined application of microbial colonization of plants and PL-coating leads to stimulation of plant growth much stronger (2.4 times more) than separately only PL-coating (1.3 times) or colonization (2.1 times) according to the data shown in Fig. 4. 
A)

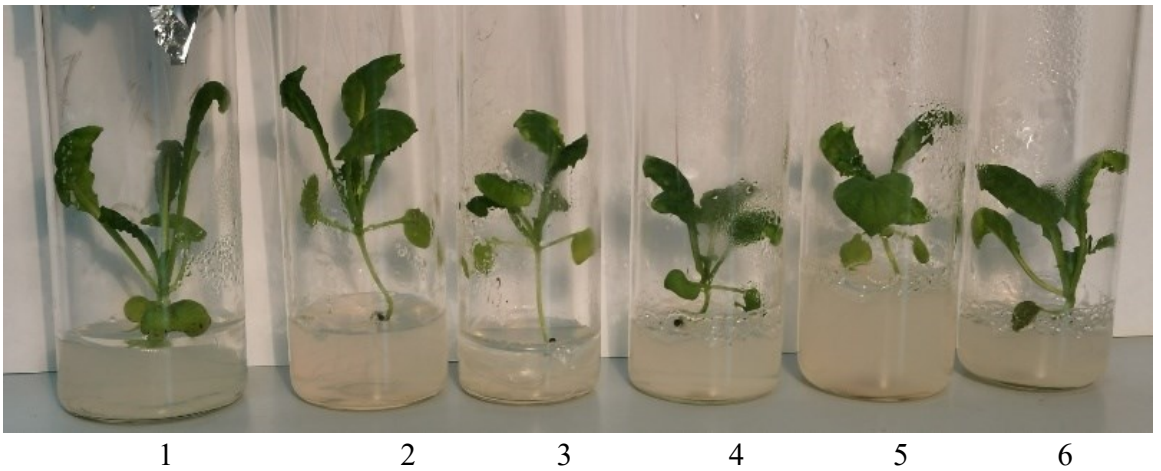

B)

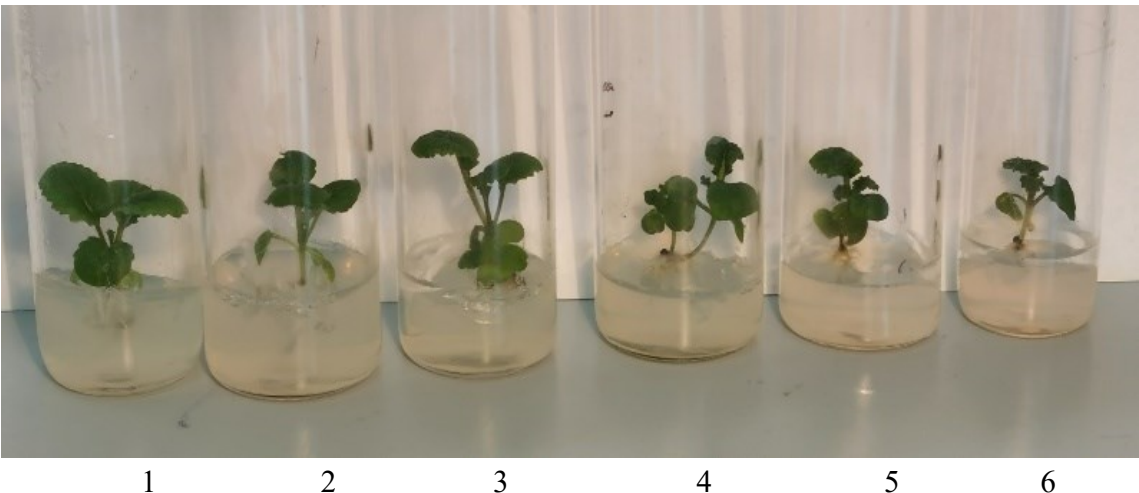

Fig. 3. Plants Brassica juncea in vitro (2 weeks), colonized by Rh. erythropolis X5 strain. A - 1-3 under spunbond with PL, 4-6 under spunbond without PL; B - not colonized. 1-3 - with PL; 4-6 without PL.

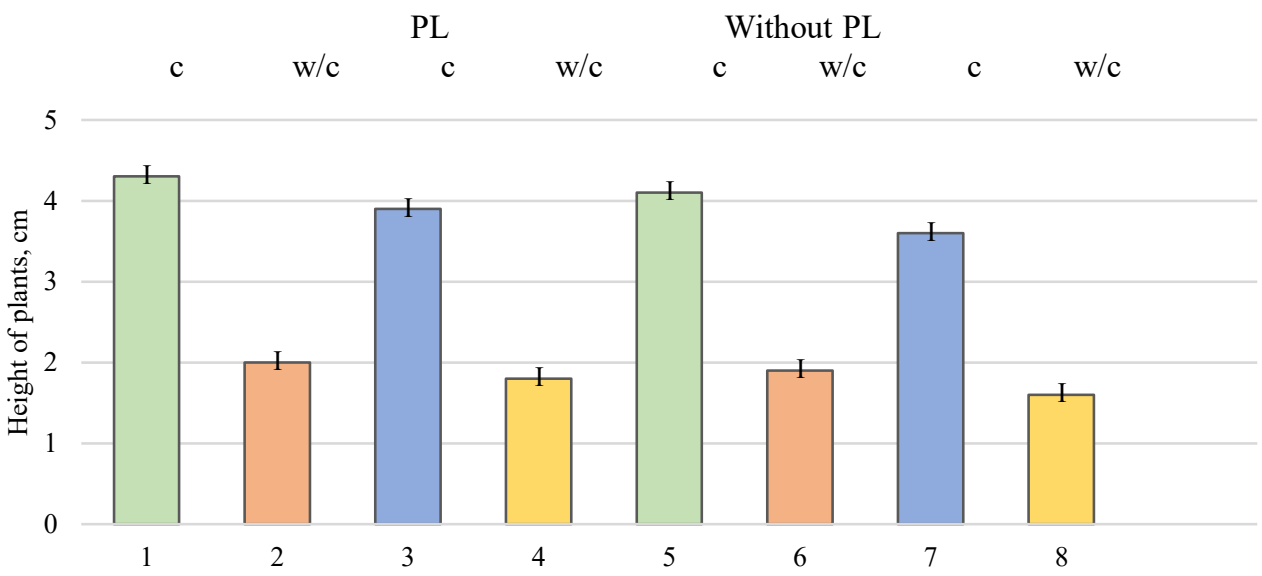

Fig. 4. Growth rate of Sarepta mustard plants (2 weeks) depending on colonization and photoluminophore coating (spunbond with PL or without PL). 1-4 PL.; 5-8 - without PL; 1,2 and 5,6P. putida; 3, 4 and 7, 8 - Rh. erythropolis $\mathrm{X} 5 ; 1,3,5,7$ colonization; $2,4,6$, 8 without colonization. 
A)

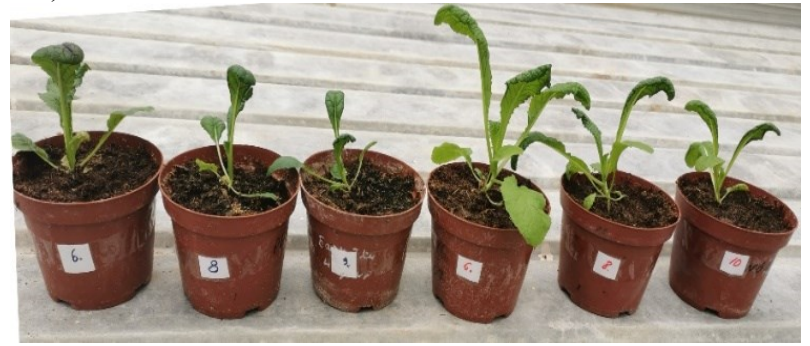

1

C)

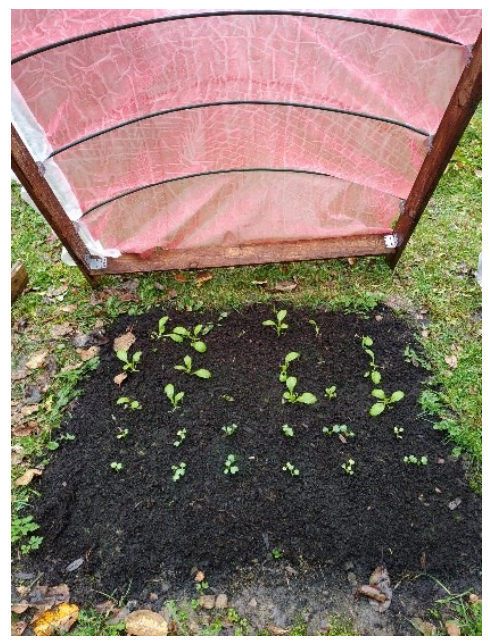

$5 \quad 6$

D)
B)

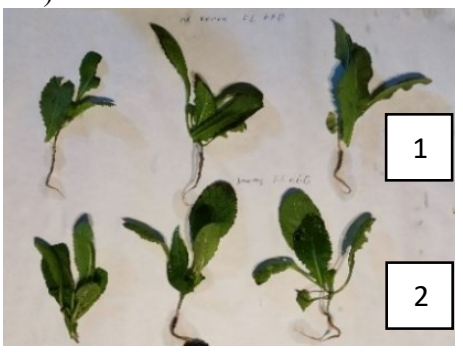

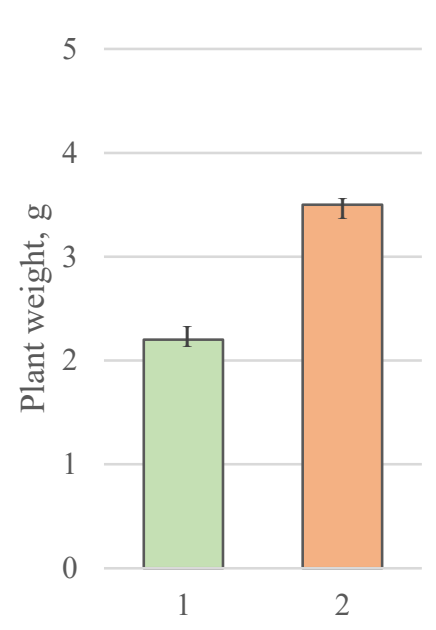

Fig. 5. Mustard plants in vivo. A - in the greenhouse of the Biotron artificial climate station; 1-3with PL, without colonization; 4-6 - with PL and colonization; B - the appearance of plants extracted from the soil: 1- with PL, without colonization; 2 - with PL and colonization; $\mathrm{C}$ - plants in the experimental site; D - weight of 2-month-old mustard plants. 1- with PL, without colonization; 2 with PL and colonization.

Laboratory studies of the colonization and PL-coatings in vitro conditions are a convenient model for studying the mechanisms of photoregulatory systems. Previously, photoregulatory systems in plants and microorganisms under the action of PL were studied separately [8]. In this work we have shown for the first time the possibility of their joint action (synergy) - the stimulation of plant growth with the PL is improved in combination with individual microorganisms. The combined effect of colonization and light-correcting films exceeds the actions of each of these factors alone. Moreover, in the final study in the open ground (Fig. 5C), for the plants grown in the laboratory in vitro and transferred to the open ground to an experimental site with PL- coating, the weight was significantly (1.5 times) higher $(3.5 \pm 0.8 \mathrm{~g})$ than in noncolonized plants $(2.2 \pm 0.6 \mathrm{~g})$, respectively which confirms the stimulating effect of PL coatings in combination with colonization by beneficial microflora. 


\section{Conclusions}

To sum up, from the results obtained and reported above the following conclusions can be drawn: 1) Red photoluminophore coating stimulates the growth of Pseudomonas putida bacteria. 2) Inoculation of Mustard plants by the bacteria P. putida and Rh. erythropolis X5 led to their stable association. 3) Colonized plants accelerate growth. 4) Red photoluminophore coating stimulates the growth of plants and especially colonized, both in vitro conditions and in open and closed ground conditions. 5) The development of studies of molecular and physiological processes of interaction of plants with associative microorganisms under the influence of red light is promising both for fundamental biological science and for agrotechnical practice.

\section{Acknowledgements}

The authors are grateful to D.O. Balakirev and Yu.N. Luponosov (Enikolopov Institute of Synthetic Polymeric, Russian Academy of Sciences) for the manufacture and provision of PL-containing agrotextiles for experiments. The work was financially supported by Ministry of Science and Higher Education of Russian Federation [the State Assignments Numbers 075-00381-21-00 and 0101-2019-0037] with the partial financial support from the Russian Foundation for Basic Research [Grants Numbers 18-29-17073, 19-08-00375].

\section{References}

1. I.F. Golovatskaya, R.A. Karnachuk, R.I. Leshchuk, A.S. Minich, S.A. Bol'shakova, G.A. Tolstikov, Sel'skokhoz, Biol., 5, 45 (2002)

2. R. N. Khramov, V. D. Kreslavski, E. A. Svidchenko, N. M. Surin, A. A. Kosobryukhov, Opt. Express. 27(22), 31967 (2019)

3. V.S. Raida, A.S. Ivanitskii, A.V. Bushkov, O.S. Andrienko, G.A. Tolstikov, Opt. Atmos. Okeana. 16(12), 1126 (2003)

4. J.W. Kloepper, M.N. Schroth, T.D. Miller, Phytopathology. 70, 1078 (1980)

5. G. Welbaum, A.V. Sturz., Z. Dong., J. Nowak, Crit. Rev. Plant Sci. 23, 175 (2004)

6. C.L. Patten, B.R. Glick, Appl Environ Microbiol. 68(8), 3795 (2002)

7. L.I. Svarovskaya, L.K. Altunina, D.A. Filatov, Prikl. Biokhim. Mikrobiol., Appl. Biochem. Microbiol. 44(6), 585 (2008)

8. D.A. Filatov, L.I. Svarovskaya, V.S. Ovsyannikova, L.K. Altunina, Microbiology. 80(2), 158 (2011)

9. T. Murashige, F. Skoog, Physiol. Plant. 15, 473 (1962)

10. Yu.N. Luponosov, A.N. Solodukhin, D.O. Balakirev, N.M. Surin, E.A. Svidchenko, S. A. Pisarev, Y.V. Fedorov, S.A. Ponomarenko, Dyes and Pigments, 179, 108397 (2020)

11. Yu.N. Luponosov, A.N. Solodukhin, A.L. Mannanov, P.S. Savchenko, B.A.L. Raul., N.M. Surin, S. M. Peregudova, A.V. Bakirov, M.A. Shcherbina, S.N. Chvalun, M.S. Pshenichnikov, D.Yu, Paraschuk, S.A. Ponomarenko, Materials Today Energy, 22, 100863 (2021)

12. Chang C.Y., Solodukhin A.N., Liao S.Y., Mahesh K.P.O., Hsu C.L., Ponomarenko S.A., Luponosov Yu. N., Chao Yu-C., J. Mater. Chem. C 7, 8634 (2019).

13. Smalla, H. Heuer, A Gotz, D. Niemeyer, E. Krogerreck-lenfort, E. Tietze, Appl. Environ. Microbiol. 66, 4854 (2000) 
14. Y. Delegan, L. Valentovich, K. Petrikov, A. Vetrova, A. Akhremchuk, V. Akimov, Microbiology. 8(48), e01234-19 (2019)

15. T. Maniatis, E.F. Frisch, J. Sambrook. Molecular cloning: a laboratory manual. NewYork: Cold Spring Harbor Laboratory Press, 2230 (1982)

16. S.L. Kandel, P.M. Joubert, S.L. Doty, Microorganisms. 5(4), 77 (2017)

17. T.I. Karu, Health Phys. 56, 1245 (1989) 